\title{
SOCIAL FABRIC AND DIFFUSION OF AGRICULTURAL INVENTORY: A MICRO LEVEL STUDY OF NAYABAAS VILLAGE, ROHTAK, HARYANA.
}

\author{
Dr. Tejbir Singh Rana ${ }^{1}$, Dr. Bharat Ratnu ${ }^{2}$, Mr. Sumit Dahiya ${ }^{3}$ \\ ${ }^{1}$ Associate Professor, Department of Geography, Shivaji College, University of Delhi. \\ ${ }^{2}$ Assistant Professor, Department of Geography, Shivaji College, University of Delhi. \\ ${ }^{3}$ Assistant Professor, Department of Geography, GCG, Sector14, Gurugram.
}

DOI: 10.46609/IJSSER.2020.v05i05.006 URL:https://doi.org/10.46609/IJSSER.2020.v05i05.006

\begin{abstract}
Agriculture is the mainstay of most of the developing nations of the world. The existence of a sound agriculture system is an indicator of economic prosperity and food security of a country. With the change in world demographics and the adjustments underway in the economic and market equations, agriculture needs to orient itself in such a way that it successfully deals with the forthcoming challenges. This paper studies the state of agriculture and related activities in Nayabaas village, Rohtak, Haryana. It deals with the limitations of farmers to switch over to modern farm technology and highlight the nature of monoculture at the cost of crop diversity. The paper also tries to figure out the effect of the local social situation on the agricultural foothold. At last, the paper recommends some measures which can account for transforming agriculture into a diversified enterprise, in the research area.
\end{abstract}

Keywords: Social structure, Marginalization, Female Work Participation Rate, Allied activities, Crop Diversity, Sustenance.

\section{INTRODUCTION}

Agriculture is the science and art of cultivation on the soil, raising crops and rearing livestock. [1] The state of Haryana is one of the few regions of the country, where the Green revolution has been the most impactful. The state has played a major role in ensuring food security for the whole country. Agriculture in Haryana is like the life line for its people as a very large chunk of its population still derives its sustenance and livelihood from it. The culture of Haryana is also deeply embedded in its farming virtues. It is the part of Sutlej and Yamuna plain which is known 


\section{International Journal of Social Science and Economic Research}

ISSN: $2455-8834$

Volume: 05, Issue: 05 "May 2020"

as the "Bread Basket of India". Haryana has been in the forefront in terms of adoption of latest technologies in agriculture and is also counted as one of the leading states for agricultural production in the country [2]. In the given scenario, agriculture as an economic activity is witnessing a structural transition in selection, production and supply chain of crops. It is not only about producing the conventional farm products and selling them exclusively at the local market. In fact, farmers and agricultural enterprises are willing to be the part of a newly expanding world market. They have not only to take into consideration customers' preferences whom they want to serve, but also have to adhere to trade regulations and maintain the standards and quality of the products[3].

The strategy of Green revolution and numerous governmental policies in the past, have favoured a particular cropping pattern in the state of Haryana. Several scholars, recently, as well as in the near past, have pointed to the skewed selection of crops by the farmers in the state. Arguably, the commercial orientation of the state's agriculture can be identified with the focus on some specific crops, particularly, wheat and paddy. As a consequence, these crops have witnessed an expansion in their cultivated area and the production, but only at the expense of other crops. The inadvertent preference for paddy and wheat has not only caused the poor health of soils but it also carries implications for the future agricultural output. The increasing replacement of traditional crops such as maize, jowar, pulses, millets and bajra has disturbed the dietary habits in rural areas. This phenomenon has contributed towards the mounting of economic constraints on the poor, and also it has marginalised them further by denying them an affordable source of nutrition. Modern day agriculture depends heavily on engineering and technology inputs and the developments in biological and physical sciences [4]. Naturally, there has been a high demand for the various agricultural inputs since the inception of the agricultural revolution and the period beyond. One such indispensable input has been the use of insecticides and pesticides. The unabated use of chemicals for increased farm output has been causing serious health problems to the farmers and consumers alike. There cannot be denial to the fact that the state has pursued progressive policies to strengthen the agriculture system, importantly through enhancing investments, promoting research and development system, streamlining public distribution system, emphasizing irrigation development, provisioning subsidies towards credit and power use, market, power generation and supply, etc. [5]. But the increase in agricultural production has been made possible only by paying a cost in the form of deterioration of natural resources and serious health implications as all.

\section{OBJECTIVES OF STUDY}

1. To present an agricultural profile and analyse the impacts of social structure on the agriculture system in the Nayabaas village. 
2. To examine the impact of use of traditional methods of agriculture in Nayabaas village.

3. To analyse the potential and scope of allied activities related to agriculture in the Nayabaas village.

\section{STUDY AREA}

This micro level study analysed the agricultural status of Nayabaas Village located in Sampla Tehsil of Rohtak district of Haryana. The village is located in close proximity to the national highway no. 10 near Bahadurgarh modal industrial township on 28.89 north latitude and 76.59 east longitude. The village is located on old alluvium bangar plains at an altitude of about 222 metres above the Mean Sea Level with ground water level at a depth of around 50-60 metres. The natural vegetation is mainly tropical dry deciduous and thorny with rough bark, waxy leaves and succulent roots as acacia, sheesham, neem, peepal and jaal trees. It is the habitat of a variety of birds and wild animal species such as Nilgai, Black Buck, Mongoose, Myna and Black Patridge etc. A few artificially developed ponds on village common land are located in the vicinity of the village, named as Dareshwala. During monsoonal rain these local reservoirs accumulate water from peripheral areas and nowadays household waste water is also drained into them. As per the 2011 census of Rohtak district, the percentage of Cultivators to Total workers was $27.7 \%$, whereas the ratio of Agricultural Labourers to Total Workers was $10.6 \%$. Whereas, the Work Participation Rate (WPR) for males is $48 \%$, but it was only $14.9 \%$ for the females. Mixed farming is the main source of livelihood of people. Women folk involved in farming are not incorporated as workers as they are mainly involved in livestock rearing and household activities. 


\section{International Journal of Social Science and Economic Research}

ISSN: $2455-8834$

Volume: 05, Issue: 05 "May 2020"

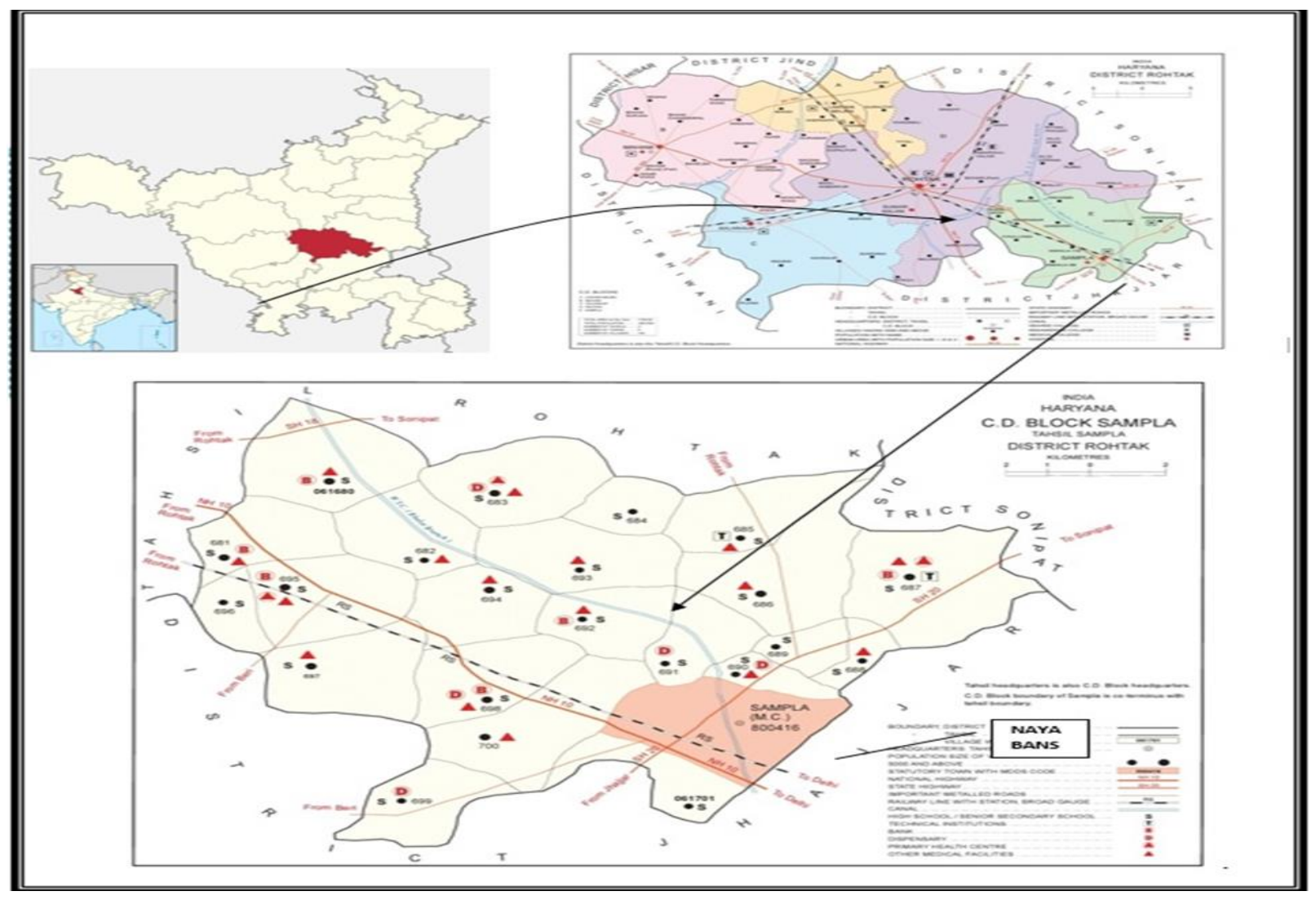

\section{DATABASE AND METHODOLOGY}

This study paper tries to assess and find out the state of agriculture at micro level in a small village (Nayabaas) of Haryana. It tries to incorporate all the relevant facets of agriculture in the village. It attempts to test the hypothesis related to the modus-operandi of transformation of agricultural strategies of the farmers to bring the desired changes in accordance to the diffusion of innovations and socio-economic combinations in society.

Database used in this paper has been extracted and compiled from the varied sources:

1. Primary Database: The research paper mainly studies the issues that have been figured out and identified from the primary data collected during the survey. It also takes into account the direct observations made and the narrations provided thereto by the various stakeholders. Both formal and informal interaction was accomplished.

The data has been collected through the direct interaction and individual interviews with a diverse sample of farmers. It encompassed both the male and female farmers, in the different age cohorts representing all the social and economic strata. They were asked questions based on specific questionnaires prepared for the purpose of the study. Their 
comments on the agricultural issues, based on their deep insights and experiences were documented along with. The method adopted was random stratified sampling.

2. Secondary Database: The research paper also takes into consideration the data collected from the secondary sources to strengthen and consolidate the postulations discussed and presented in the report. It was taken from District Census handbook Rohtak, Village and town wise primary census abstract (PCA), Series-07 Part 12-B, Directorate of census operations, Haryana, Census of India, 2011.

\section{ANALYSIS}

The distribution of farmlands in Nayabaas village are highly unequal among the various social groups based on caste system. Arguably, the reason for such skewed distribution lies deeply buried in the feudal history of the society. In feudalistic society, the farmland holdings were believed to be the privilege of certain castes based on occupation and ancestry. The people of landless castes were made to earn their livelihood through their certain skills for allied services to all sections of self enclosed rural society.

Figure1. Distribution of Total Farmland Among Different Social Groups in Nayabaas Village, District Rohtak, Haryana.

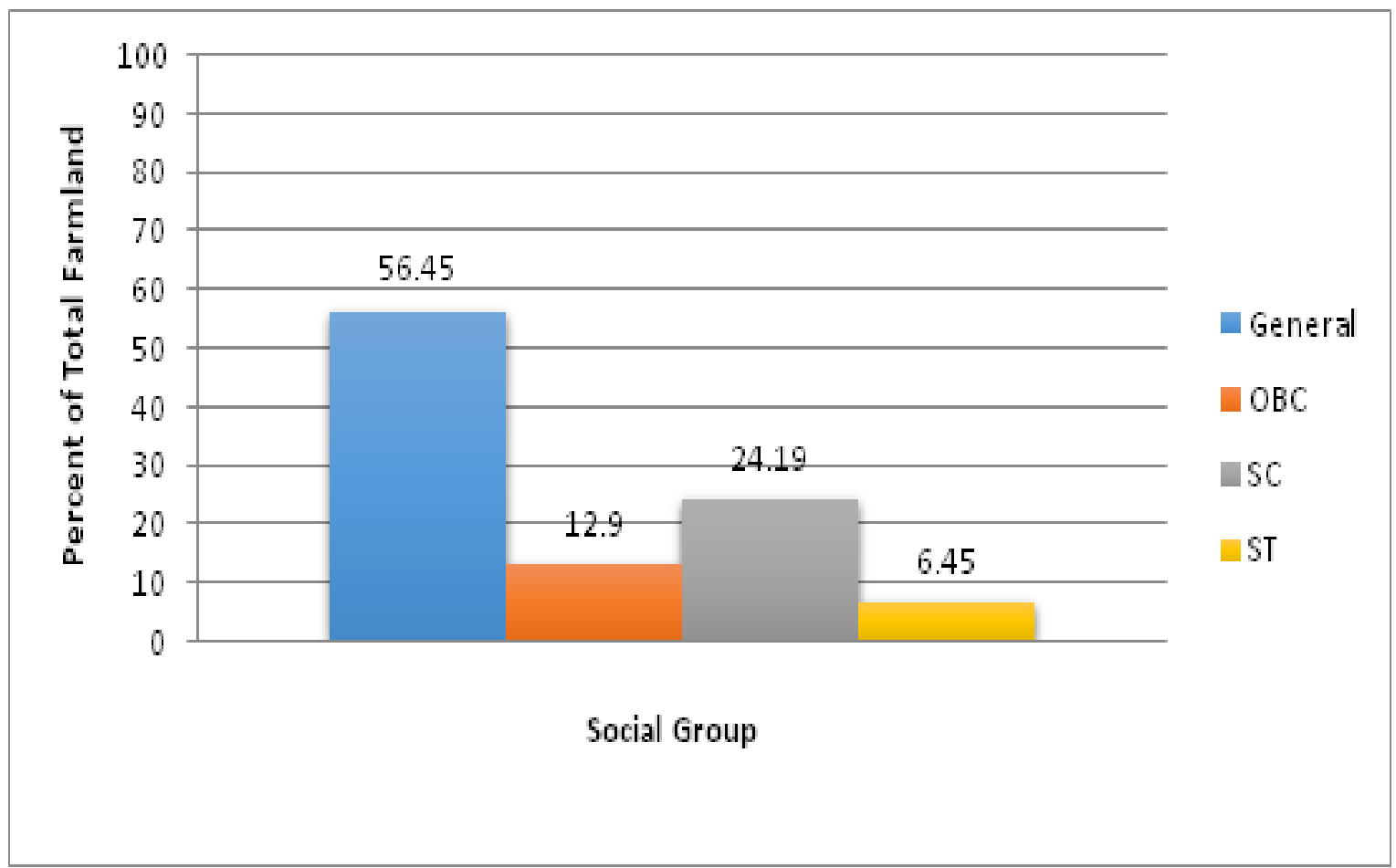

Source: Primary data collected from survey. 
International Journal of Social Science and Economic Research

ISSN: $2455-8834$

Volume: 05, Issue: 05 "May 2020"

\section{Table 1: Distribution of Total Farmland Among Different Social Groups in Nayabaas Village, District Rohtak, Haryana.}

\begin{tabular}{|l|l|l|l|l|}
\hline Category & General & OBC & SC & ST \\
\hline $\begin{array}{l}\text { \% of farmland } \\
\text { holdings. }\end{array}$ & $\mathbf{5 6 . 4 5 \%}$ & $\mathbf{1 2 . 9 0 \%}$ & $\mathbf{2 4 . 1 9 \%}$ & $\mathbf{6 . 4 6 \%}$ \\
\hline
\end{tabular}

Source: Primary Data collected from survey.

The primary data collected from the village shows that the people belonging to the general category own most of the farmlands of the village which control the rural economy. Not surprisingly, all the big tracts of the farmlands are possessed by a few, invariably belonging to the certain castes engaged in farming since generations. The other social groups (mainly artisans) who belong to the different castes are left with a smaller share of farmland ownership as OBCs (12.9\%), SCs (24.19\%), and STs $(6.45 \%)$ respectively. The data also points to a significant pattern, wherein the average size of farmland holdings among these social groups is too small and therefore, the cultivation of foodgrains meant for subsistence and self consumption is the most obvious choice. As such, with the small size of farmland holdings there is little or no scope left for the commercialization of crops.

Figure 2: Number of Households cultivating different crops (1990 \& 2016) in Nayabaas Village, District Rohtak, Haryana

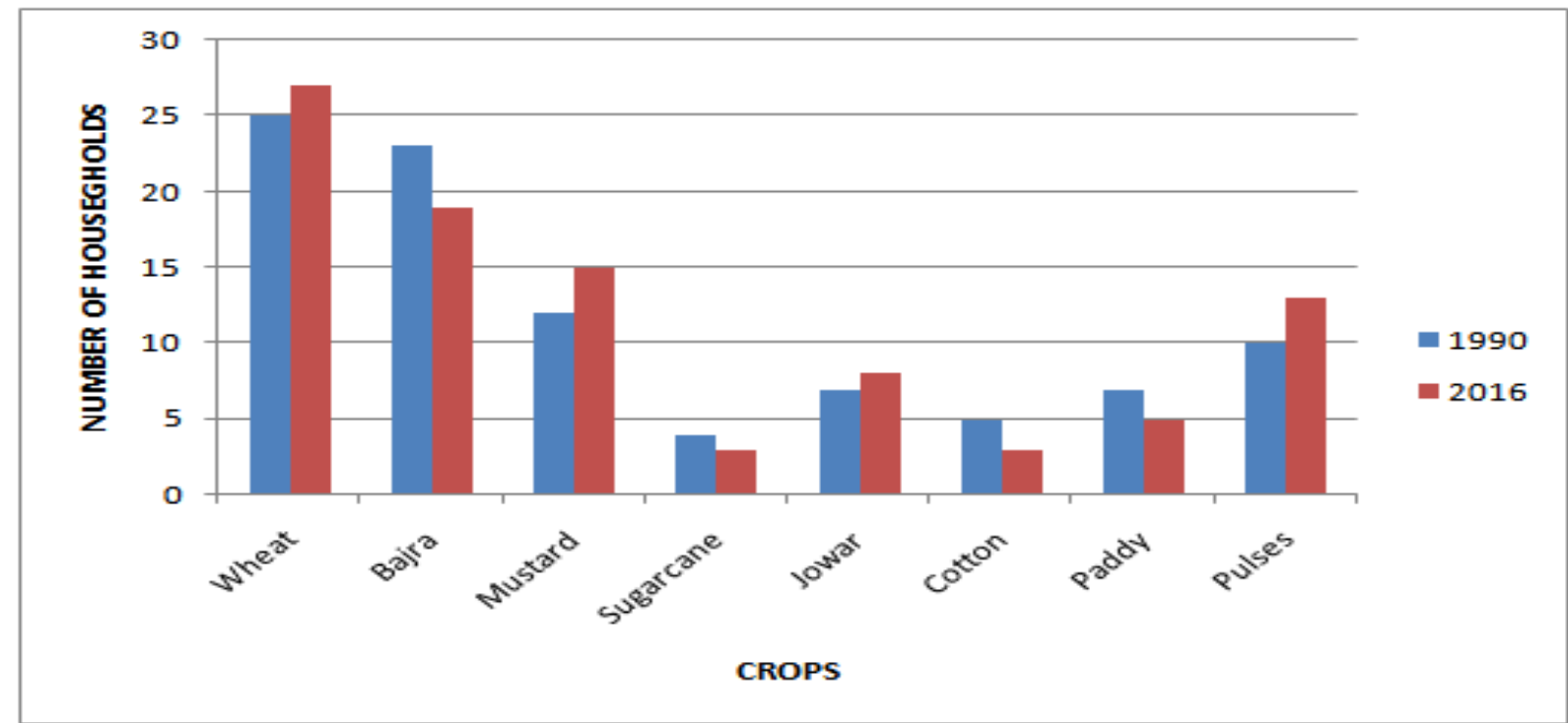

Source: Primary data collected from field survey. 
Table 2: Number of Households cultivating different crops (1990 \& 2016) in Nayabaas Village, District Rohtak, Haryana

\begin{tabular}{|l|l|l|l|l|l|l|l|l|}
\hline Year & Wheat & Bajra & Mustard & Sugarcane & Jowar & Cotton & Paddy & Pulses \\
\hline 1990 & 25 & 23 & 12 & 4 & 7 & 5 & 7 & 10 \\
\hline 2016 & 27 & 19 & 15 & 3 & 8 & 3 & 5 & 13 \\
\hline
\end{tabular}

Source: Primary data collected from field survey. (Unit: Quintal per acre farmland)

The Green revolution and the related policies have gradually altered the cropping system of the state in favour of foodgrain crops. Such a choice for the foodgrain crops was considered necessary to ensure the food and economic security of individual farmers. The post-liberalization period has been marked by instances of diversification of crop cultivation and change in cropping pattern. However, the primary data collected from field-survey shows that the preference for certain crops by the households have not undergone any significant change in almost two decades. Wheat, Bajra, Mustard and Pulses have remained the principal crops during the period. The above table 2 , shows that the average number of households growing wheat, bajra, mustard, sugarcane, jowar, cotton, paddy and pulse have marginally changed by $2,4,3,1$, 1, 2, 2 and 3 households, respectively.

Figure 3: Percentage of Households Using Different Farm-Inputs in Nayabaas Village, District Rohtak, Haryana

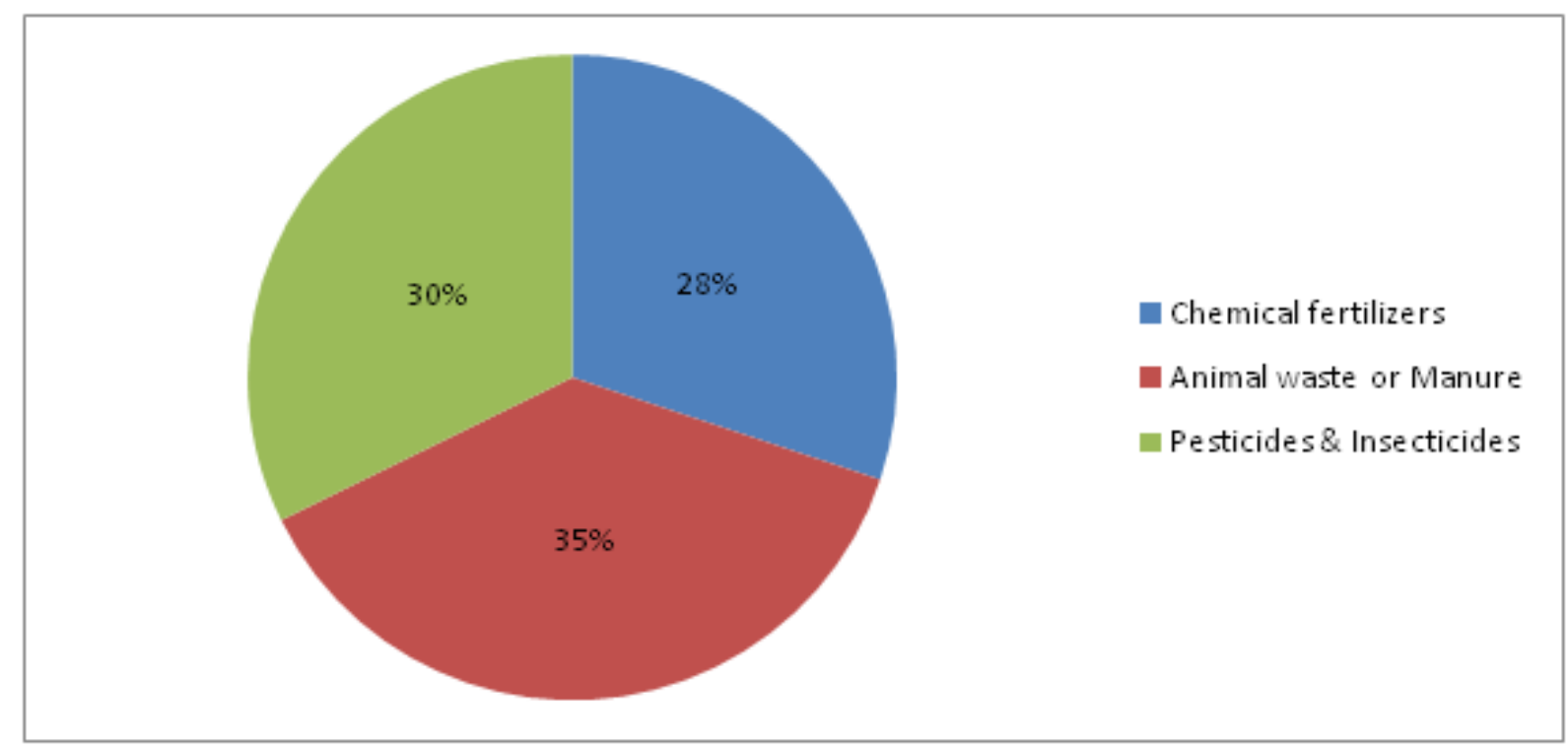

Source: Primary data collected from field survey. 
Table 3: Percentage of Households using Different Farm Inputs in Nayabaas Village, District Rohtak, Haryana

\begin{tabular}{|lr|l|l|l|}
\hline $\begin{array}{l}\text { Category of Farm } \\
\text { Inputs }\end{array}$ & Chemical Fertilizers & Bio-Manures & $\begin{array}{l}\text { Pesticides and } \\
\text { Insecticides }\end{array}$ \\
\hline $\begin{array}{l}\text { Number of } \\
\text { Households }\end{array}$ & $28 \%$ & $35 \%$ & $30 \%$ \\
\hline
\end{tabular}

Source: Primary Data collected from field survey.

Farming and raising the crops in the study area is not equally profitable for all the farmers. The use of chemical fertilizers, pesticides and insecticides is applied by almost all the cultivators of the village irrespective of their caste, economic status or size of farmlands. However, the farmers with small landholdings are a bit indifferent to their use and often make use of animal waste or organic bio-manures. The big land-owning farmers, on the other hand, use both the bio-manures as well as chemical fertilizers. As the natural fallout or side effects of Green revolution, which involves the growing of high yield variety seeds with low resistance to pests, pest infestation has been a recurring problem in the areas. Therefore, most of the farmers inevitably use pesticides, insecticides and weedicides, irrespective of the size of farmlands. The above table 3 , shows that the number of households which use chemical fertilizers, organic manures and pests are $28 \%$, $35 \%$, and $30 \%$, respectively.

Figure 4: Source of Water for Irrigation at Farmlands in Nayabaas Village, District Rohtak, Haryana.

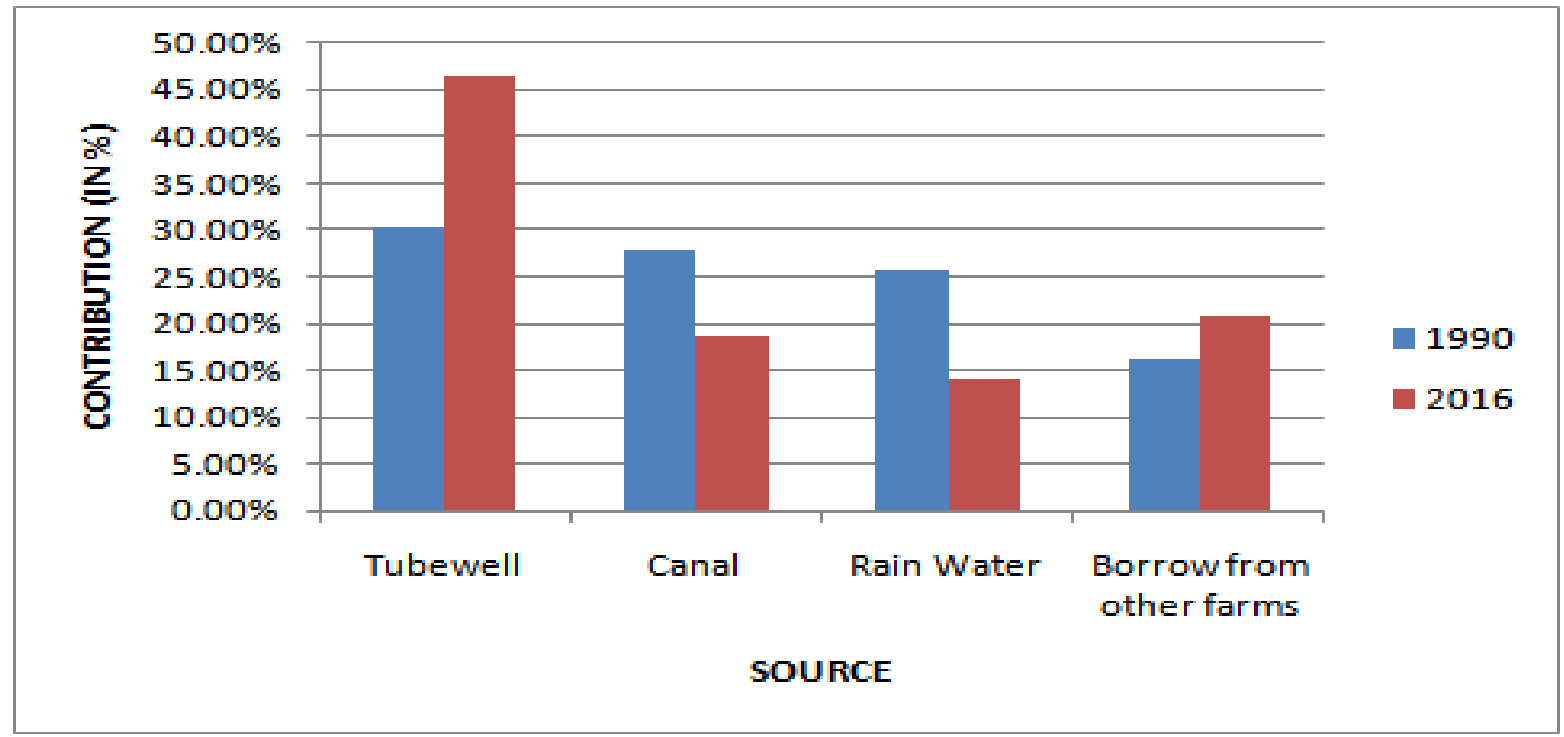

Source: Data collected from field survey. 
International Journal of Social Science and Economic Research

ISSN: 2455-8834

Volume: 05, Issue: 05 "May 2020"

Table 4: Source of Water for irrigation at farmlands of respondents.

\begin{tabular}{|l|l|l|}
\hline SOURCE & 1990 & 2016 \\
\hline Tubewell & $30.23 \%$ & $46.51 \%$ \\
\hline Canal & $27.90 \%$ & $18.61 \%$ \\
\hline Rain Water & $25.58 \%$ & $13.95 \%$ \\
\hline Borrow from other farms & $16.29 \%$ & $20.93 \%$ \\
\hline
\end{tabular}

Source: Primary data collected from field survey.

Scarcity of water at farmlands for irrigation is an acute problem for most of the farmers in the study area. The small farmers are the worst sufferer of acute water supply in their farmlands. The farmers of Nayabaas village are mainly dependent on tube wells (diesel operated), canal irrigation and rainwater for the irrigation in farmlands. The inconsistent and meagre supply of water through canals forced the farmers to deviate from its dependency for irrigation. According to the primary data collected from survey, the source of water at farmlands have shown an increasing inclination toward tubewells. The proportion of dependency on tubewell has been increased from $30.23 \%$ in 1990 to $46.51 \%$ in 2016 . The need for assured supply of water at the required time schedule of different crops enhanced the dependency on tubewells. Simultaneously, the proportion of households using canal water for irrigation has shown the declining trends from $27.90 \%$ in 1990 to $18.61 \%$ 2016. Though, the decline is only relative visa-vis the expansion in water supply through the tube well. Few farmers also borrow water from the privately owned tubewells of the neighbourhood, generally from big farmers, at a high rate of Rs. 120 per hour supply of groundwater from 3 to 4 inch diameter of pump pipe. Subsequently, assured supply of water for irrigation from tube wells reduced the dependency on rainwater. The dependency of farmers on rainwater for irrigation has decreased from $25.58 \%$ in 1990 to 13.95 $\%$. in 2016. 
Figure 5: Occupational Structure in Nayabaas village, District Rohtak, Haryana.

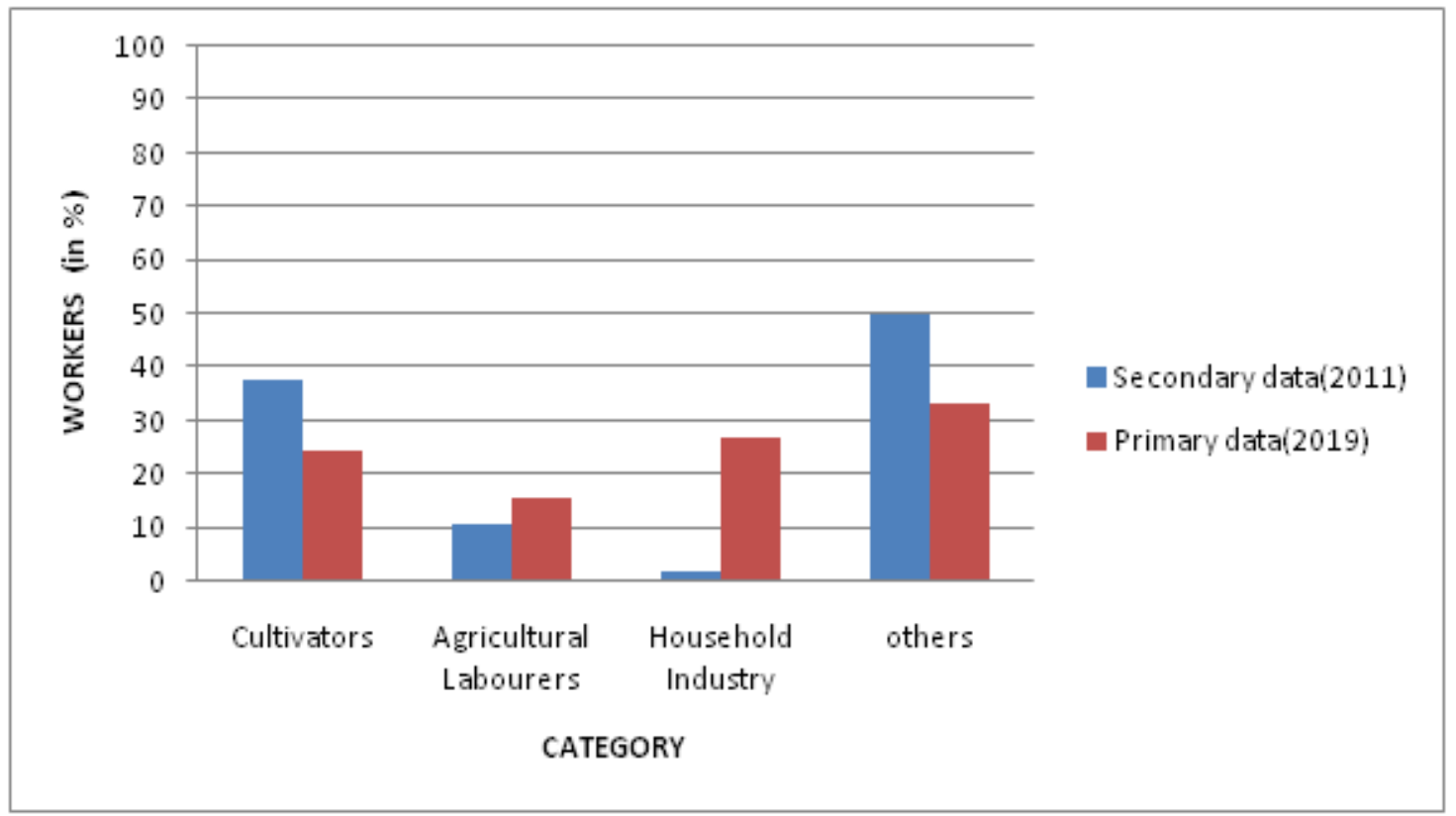

Source: Primary data from field survey and Census of India, 2011.

Table 5: Category of Workers in Nayabaas, Rohtak, Haryana.

\begin{tabular}{|c|c|c|c|c|c|c|c|c|}
\hline \multirow[t]{2}{*}{ Year } & \multicolumn{2}{|c|}{ Cultivators } & \multicolumn{2}{|c|}{$\begin{array}{l}\text { Agricultural } \\
\text { Labourer }\end{array}$} & \multicolumn{2}{|c|}{$\begin{array}{l}\text { Household Industry } \\
\text { Worker }\end{array}$} & \multirow{2}{*}{$\begin{array}{l}\text { Others } \\
\text { Male }\end{array}$} & \multirow[b]{2}{*}{ Female } \\
\hline & Male & Female & Male & Female & Male & Female & & \\
\hline 2011 & $29.8 \%$ & $7.58 \%$ & $9.9 \%$ & $0.77 \%$ & $1.7 \%$ & $0.15 \%$ & $44.8 \%$ & $5.10 \%$ \\
\hline 2019 & $18.03 \%$ & $6.5 \%$ & $10.31 \%$ & $4.9 \%$ & $6.01 \%$ & $20.76 \%$ & $26.2 \%$ & $7.10 \%$ \\
\hline
\end{tabular}

Source: Primary data collected from field survey and Census of India, 2011.

Based on a comparative analysis of the census data and the primary data collected from the village, for the different categories of workers, the following observations have been recorded. The proportion of mainstream cultivators in the village have decreased from $37.4 \%$ in 1990 to $24.5 \%$ in 2016, wherein, the participation rate for both, males (29.8\% to 18.03\%) and females ( $7.58 \%$ to $6.50 \%$ ) have decreased in the same time period. The share of agricultural labourers has increased from $10.6 \%$ in 1990 to $15.3 \%$ in 2016, but the rate of increase is greater for the females $(0.77 \%$ to $4.9 \%)$ than the males $(9.9 \%$ to $10.3 \%)$. The household industry workers have seen a boom in the last few years witnessing an increase in its percentage of share from $1.8 \%$ to $26.7 \%$. Interestingly, the females account for the majority of this increase $(0.15 \%$ to $20.76 \%)$ 


\section{International Journal of Social Science and Economic Research}

ISSN: $2455-8834$

Volume: 05, Issue: 05 "May 2020"

unlike males (1.7\% to $6.01 \%)$. The data highlights a healthy trend of increased female work participation rate as a definite sign of positive change in the perception of society.

\section{DISCUSSION AND RESULTS}

The culture of Haryana is deeply embedded in the agricultural practises as the livelihood and sustenance of most of the residents is derived from farmlands. The case of Nayabaas village provides no different circumstance. The different aspects of the condition of agriculture in the village can be considered through an appraisal of the general social setting, in the wake of agriculture related developments in the state as a whole. Following points present an abridged picture of it.

Small Landholdings and Marginalisation: The persistence of extreme inequality in the countryside and the preponderance of small and marginal farmers with limited resources pose the most important institutional challenge in India. An evaluation of the implementation of land reforms brings out that reforms in India achieved only a partial success. Whereas the legislation succeeded in the matter of abolition of intermediaries, other objectives of land reforms namely tenancy reforms and ceilings on landholdings were only partially realised. Accordingly, the partial success of land reforms is attributable to the fact that the reform measures were generally promulgated by the ruling elites composed of or electorally dependent on the upper echelons of agrarian society. It can be argued that the success of the land reforms depended on the strength of the peasant movement. [6] It can be contented that the land reforms have failed to be implemented in the state of Haryana. Moreover, no effective peasant movement aimed at causing a more egalitarian ordering in the countryside did ever take hold. The society of Haryana remained one of the staunchest followers of the established social norms such that it was always central in assigning economic activities to the different social groups.

Further it has been argued by Bhalla that in the irrigated regions, the self cultivating semi medium and middle peasantry was able to derive optimum benefits from new seed-fertilizer technology. The political fallout of this development was that the well-to-do peasantry also became politically very powerful over time. Accordingly, this development strengthened extremely retrogressive factors, one of them being the caste. Within the same perspective it is therefore contended that the Nayabaas village represents a miniature of such societal set-up, and it continues to bear similar influences as its dependence on agriculture and the related activities remains complete. Majority of those who occupy the top slot in such an arrangement continue to be its main beneficiary. However its brunt is felt to the maximum by those who lie lowest socially and economically, as they are pushed further into acute marginalization i.e. they have got very little or no land to cultivate. 


\section{International Journal of Social Science and Economic Research}

ISSN: $2455-8834$

Volume: 05, Issue: 05 "May 2020"

The primary data collected from the village testifies this observation. General category farmers possess the highest share in the cultivated land. On the other hand, per capita cultivable farmland available with the SCs does not exceed 1 or 2 bigha. This gap produced in land sizes is largely the result of social equations into play. However, it is now turning around as the biggest stumbling block in the economic betterment of the economically excluded section of the village. It discourages the agricultural spirit among them promoting no overall welfare. Due to their small landholdings of farmlands, the agriculture has become uneconomical and non profitable to them. In fact, the income is too meagre to allow them to try any other avenues of livelihood and earning. Therefore, a definite cause-effect relationship is imagined wherein the low income generated from the crop farming brings little capital to invest in the subsidiary fields or to generate additional income.

Livestock Factor: Interestingly, it was also observed that the number and quality of livestock and cattle bears a correlation to social classes and therefore, the size of land holdings in the Nayabaas village. The class and caste barriers which are generally cut across in performance of certain agriculture-related tasks are especially noticeable in animal husbandry work. Animal husbandry has gained a new importance in view of the intense commercialization of milk. On account of fairly low cost of maintenance, indigenous breeds of cows are kept by the economically weaker sections. The cross-bred exotic cattle though far superior to the indigenous cows are far more expensive to maintain which only the more affluent landowners-cum-dairy farmers can afford. [7]

Further, the practice of animal husbandry ensures an inexpensive source of milk. The small farmers also make some returns by selling calves. The bullock continues to garner some importance in the still prevalent traditional farming techniques such that it is still used as a draught animal and bullock cart is still prevalent in transporting the agricultural produce to the local markets.

Inadequate Crop Diversification: Indian agriculture is, in a way, a victim of its own success, which over the time is posing to be a major threat. Indian agriculture has become cereal-centric and as a result, regionally biased and input-intensive, consuming general amounts of land, water, and fertilizer. [8]

The primary data collected from a field survey in the Nayabaas village shows that the practice of allotting preference to only a few crops by the households have not undergone any significant change in recent past almost two decades. Wheat, Bajra, Jowar, Mustard, green fodder and Pulses have remained the principal crops over the period. Therefore, there has been an almost negligible instance of diversity in the cropping patterns. Such status quo can be considered to be explained through the following two factors, viz. 


\section{International Journal of Social Science and Economic Research}

ISSN: $2455-8834$

Volume: 05, Issue: 05 "May 2020"

A. Small size of landholdings - The average landholding size is small in the village. Consequently, the capacity of the farmers to make high capital investments or to afford risks is low. Most of the cultivable land is used for growing food grain crops to fulfil the domestic and local consumption demands. The cash crops and the non-food grain crops are less in vogue.

B. Water Unavailability - Agro-economically, the green revolution has etched Haryana predominantly into three regions and two sub-regions. The second most prosperous area runs into broad west to east belt across the middle of Haryana covering most of Hissar and parts of Rohtak district. Although 62 percent of its total cropped area is irrigated from the agricultural point of view, this irrigation is not available to the farmers in the quantity and at the time it is wanted. [9] Scarcity of affordable water is another problem for the small farmers as they find it illogical to install a tube well for small pieces of land. Also it requires substantial initial investments as well as continued expenses for its operation. The network of canal has not proved much as a blessing for them as most of the time they run with little or no water. The source of canal water is far away so that when it reaches its destination it has almost lost its velocity and as well as its amount. Time for every farmland has been fixed according to their landholding size and location. But the flip side of it is that the formula devised to release water in the fields have been designed with a fixed amount and velocity of flowing water, so that when it falls below it, which in fact is the case most of the time, it fails in providing that postulated amount of water. The trend of increasing resort to the tube well irrigation also corroborates the above situation.

So it becomes least acceptable for farmers to even venture with the idea of growing different crops in lieu of lack of assured supply of water. Only a few of them, with large landholding and tube well grow cash crops like Mustard, and sugarcane.

Increased Female Work Participation Rate: The share of agricultural labourers has increased from $10.6 \%$ in 1990 to $15.3 \%$ in 2016 , but the rate of increase is greater for the females $(0.77 \%$ to $4.9 \%$ ) than the males $(9.9 \%$ to $10.3 \%)$. The household industry workers have seen a boom in the last few years witnessing an increase in its share from $1.8 \%$ to $26.7 \%$. Interestingly, the females account for the majority of this increase from $0.15 \%$ to $20.76 \%$.

Chowdhary has argued that the small farmers have adopted the new agricultural strategy but their investment capacity has been modest. They try to make up this deficiency by making use of family labour and in some cases by the hiring of labour. In such a case, females did not, infact could not be withdrawn from agriculture. The green revolution, whatever the size of land holding, shows an increase in demand for labour of all kinds of purposes. The demand has increased for different tasks such as multi-cropping, greater care in sowing, transplantation, weeding, pesticide control, etc. Because the process of farm mechanization is still incomplete, the additional labour demands remain intact. In such a scenario of perennial labour demand and 
International Journal of Social Science and Economic Research

ISSN: $2455-8834$

Volume: 05, Issue: 05 "May 2020"

the ever escalating labour costs (especially after the launch of MGNREGA), women continue to work. The reinforced sector of animal husbandry in the last few decades has meant an increased female labour participation in the farm sector.

\section{SUGGESTIONS}

\section{Mixed cropping and Crop diversification-}

Absence of different crops decreases the overall or net productivity of the big farmers. Therefore a change in land use pattern is suggested. To realize the optimum potential of the field the land use pattern can be transformed by adopting mixed farming i.e. by adding other crops amid the regular crops according to the suitability of the climate. This can enhance the farm productivity and add diversity to it. Eg: the cultivation of flowers and vegetables of various types can be conveniently added to the existing crops.

- Value addition activity-

Value addition to the raw materials can prove to be an income enhancing option to the farmers. This will directly link their fields with the market economy. Micro level processing units may be established for value addition of farm products with ensured market linkages. Market oriented farm products with perennial supply like poultry, piggery and milk processing units may be established to supply the end product directly to consumers with increasing return.

\section{- Conservation techniques -}

The farming techniques of Nayabaas village are found to be in transitional stage and partly obsolete. It does not really mean that the farming system as a whole is not suitable for the area. There have been a lot of challenges and opportunities faced by the farmers such as a changing market scenario, greater demand for foodgrains due to increased population and economy of diminishing return of farm products etc. The new means of production can enhance the farm productivity. The methods of farming in Nayabaas were found to be equipped with following demerits:

(A) Carpet Mode of Irrigation: In this method of irrigation, the water is introduced to the field from one end which gets filled and spread from corner to corner. Water enters into the level or graded furrows or basins of the field. This mode of irrigation is best suited for the plane or slightly sloped areas, and the medium to fine textured soil types which promote the lateral spread of water down the furrow row or across the basin. The farmers of Nayabaas have been following this technique till now as the average size of their landholdings are small, and for whom making an investment on other means of irrigation like installation of drip and sprinkler was a thought too costly. Also the diesel engines operated pumps that were used for their tube wells could not generate enough pressure in pipes to drive sprinklers. Such a mode of 


\section{International Journal of Social Science and Economic Research}

ISSN: $2455-8834$

Volume: 05, Issue: 05 "May 2020"

irrigation will result in long term negative consequences such as the ground water table may deplete, which will only make the situation worse particularly for small farmers.

(B) Diesel Operated Pumps: A high density of diesel- run tubewell sets in the Nayabaas village reflects the prevalence of the traditional methods of cultivation. The preponderance of carpet irrigation has been the prime reason for such a distribution. This has proved harmful not only for the depleting ground water level but has caused a lot of problems for many small, marginal and medium farmers as they find it difficult to sustain the ever-rising prices of diesel.

The investment towards irrigation in Nayabaas, has been attempted via both the routes i.e. public (canal irrigation) and private (tube wells). In both cases the water has been deployed via carpet or flood irrigation, which is an extremely inefficient use of water. Irrigation investments must shift to adopting technologies like sprinkler and drip irrigation and rainwater harvesting (leveraging labour available under the MGNREGA where possible). The technique could be used as such-

(A) For big and medium farmers, the installation of electricity operated pumps can prove useful and helpful. This will not only help them conserve water but also minimize their cost incurred on fuels.

(B) Use of sprinklers and drip irrigation be helpful in avoiding the wastage of water. The technique is well suited for the less water intensive crops like bajra, mustard, flowers and vegetables etc.

\section{- Availability of allied activities:}

For the different categories of farmers, the quantum of chances and challenges also varies. Therefore, they can make use of different opportunities to add to their earnings besides fields.

(A)For Big Farmers- Farmers with landholdings more than 10 acres of farmland have more available opportunities in regards to the allied activities. They can divide their large farms into parts and undertake the diversified cropping and mixed farming. Several other activities like rearing of bees, livestock, floriculture, etc. can also be introduced with perennial flow of money.

(B) For Small and marginal Farmers- The opportunities available with small and marginal farmers are confined to crops with certain limitations. To devote their farms for other crops can be non-viable to them. But livestock rearing for commercial dairy farming is an option apart from food grain cultivation. They can also collaborate with the big famers in their allied activities like bee keeping, poultry, etc. 


\section{International Journal of Social Science and Economic Research}

ISSN: $2455-8834$

Volume: 05, Issue: 05 "May 2020"

\section{CONCLUSION}

Agriculture in Nayabaas is not a profitable enterprise for all sections of society and its benefits are not trickling down to all social classes equally. The few farmland owning people are bestowed with more resources and the large landless section of society is left with the accessibility of a little resources. The practise of traditional methods of crop production is also a cause of concern for its limited productivity. The agricultural vision of farmers of Nayabaas village is also not optimistic due to its diminishing return. Venturing with the new ideas and avenues of enhancing their income as well profitability by inclusion of allied activities are diffusing with limited extent. Diminishing return of farm economy and rural distress are the stumbling blocks of innovative ideas among farming communities. In this regard, diffusion of agricultural education and marketing mechanisms with assured return of these allied activities can be a way forward. The Nayabaas village is an example of human resource where people from almost all strata of society live with coexistence and interdependence. But, there is a need to realize its potential and increase the agricultural profitability, thereby ensuring an overall development of the village.

Diffusion and acceptance of new farm techniques with assured return of crops can utilize the human resource and check the distress of rural out migration. The crop diversity is replaced by monoculture as only a few food grain crops dominate in the farm fields. The farmers of Nayabaas village have to rise above the notion of SUSTENANCE ONLY, and strive to make their agriculture a profitable enterprise.

\section{REFERENCES}

1. Abbas A., Introduction to Agriculture, The university of Agriculture, Peshawar, Pakistan, Ponsidha Hen, 16 sep. 2016, Page no. 5. http://www.resarchgate.net/publication/282905517

2. Anil, trends and Patterns of major crops in Haryana: A geographical Analysis, International Journal of All Research Education and Scientific Methods (IJARESM), 7 July, 2016, ISSN: 2455-6211, Vol. 4.

3. Chandra Shekara P., Balasubramani N., Farmers Handbook On Basic Agriculture, Desai Fruits \& Vegetables Pvt. Ltd., Navsari, Gujarat, India, August 2016, Second Edition Page no. 5 .

4. Indian Council of Food and Agriculture, Report on Haryana Agriculture and Farmers welfare, Page no. 2. www.icfa.org.in

5. Progressive Haryana: The Agricultural Hub of India, PHD Research Bureau, PHD chamber of Commerce and Industry and Industry, Feb. 2019, Page no. 23.

6. Bhalla, G.S., 2007, Indian Agriculture Since Independence, NBT, New Delhi, Page 38-39. 
International Journal of Social Science and Economic Research

ISSN: 2455-8834

Volume: 05, Issue: 05 "May 2020"

7. Chowdhry, Prem, 1995, "High Participation, Low Evaluation: Women and Work in Rural Haryana", Economic and Political Weekly, (December 25, 1993), pp. A140-148

8. GOI, Economic Survey, 2015-2016, Vol. 1, “Agriculture : More from Less”. pp. 68-83.

9. Bhalla, Sheila, 1976, "New Relation of Production in Haryana Agriculture", Economic and Political Weekly, (March 27, 1976), pp. A25-A30. 